\title{
Gender Dimensions of Informal Cross Border Trade in West-African Sub-Region (ECOWAS) Borders
}

\author{
S. Olabisi Yusuff \\ Department of Sociology, Lagos State University, Lagos, Nigeria \\ E-mail address: soyusuf@yahoo.co.uk
}

\begin{abstract}
The aim of this paper is to examine the dynamics of women in cross border trade along ECOWAS sub region. West African region is noted significantly for high volume of trade that goes on within its borders on daily basis, and it involves formal and informal trade. Informal trade however, is an integral, but unrecognized component of ECOWAS economic activities. Over sixty percent of women are into informal trading across ECOWAS sub region, yet, there is gap in literature on the dynamics of these regional women traders across sub- ECOWAS region. Using qualitative method of data collection, a significant number of women traders in informal cross border in sub ECOWAS region were interviewed on their motivations, trade operations, challenges, and coping strategies. The findings reveal that there are several insecurities posed by informalities of women trading practices. These insecurities are associated with activities of law- enforcement agents and touts coupled with the facts that women traders are not knowledgeable about the procedures that guide international trade. Despite several challenges posed by informal cross border trade, women traders had devised coping strategies to negotiate these challenges. Majority of women utilized income generated to support themselves, their spouses and children and above all, it had enabled them to live above poverty level, which is one of millennium goals. The paper recommends that informal economic activities of women in cross border trade needs to recognized for holistic policy to be formulated and, women need vigorous education on the law that guide the rules and procedures of regional trade.
\end{abstract}

Keywords: Dynamics; Informal; Cross Border; Women; Sub- ECOWAS Region

\section{INTRODUCTION}

Formal and informal cross-border trade in West Africa has increased since the 1990s because of economic liberalization policies, population growth, and urbanization. This expansion has been credited with deepening regional integration, improving economic growth and benefiting the population through employment, market and product diversification, increased outlets for goods produced and manufactured in the region and improvements in food availability (Morris and Saul, 2000). It has been suggested that trade in 
non-traditional exports such as agricultural products, livestock, fish, handicrafts, and manufactured goods will increasingly drive sustained economic growth in West Africa. This implies the importance of strong connections between trade and other sectors of West African economies, particularly agricultural production and processing, fisheries and manufacturing (ECOWAS-WAEMU, 2006).

Informal trade is an integral part and unrecognized component of Africa ${ }^{e e}$ s economy. Informal trade in Africa has persisted despite the effort to graft it into formal economy in developing countries (Olutayo, 2005). Evidence shows that, on average, sixty percent of trade is informal trade in African countries (Macamo, 1990, Ackello-oguta, 1998). Goldberg and Pavenik (2003) define informal as the sector of the economy that does not comply with the labour market legislation and does not provide worker's benefits. Informal trade here means trade that is not recorded officially by customs at the border and does not necessarily mean illegal trade. Now, in regards to informal cross - border trade, the history of cross border trade exchange is tied up with emergence about twenty years ago of floating exchange rates and the Eurobond market (Chichilinsky, 2003). The current economic and socio political environment of sub Saharan Africa has an increasing percentage of Sub-Saharan African "es seeking alternative livelihood strategies, some of which include high-risk activities, often time, these alternatives include cross- border trading and migration to neighbouring states (IOM South Africa Newsletter, 2010).

Cross border trade cuts across all ages, religion, ethnic groups, and gender. The main type of cross border trade practiced across West African border among women is informal cross-border trade (ICBT). ICBT plays a vital role in poverty reduction, employment, and income opportunities (Kabira, 2006, Cagatay and Ozler, 1995). It is a vital source of livelihood for the poor and an important component of Africaes economy contributing immensely to the economy of Africa, particularly, in terms of economic upliftment of women status, food security, regional economic trade and social integration (Matsuyama, 2011). ICBT does not occur in vacuum as it takes place within the broader trade and developmental context internationally, regionally and nationally. There is a direct link in West Africa between CBT, trade openness and regional economic growth (Morris and Saul, 2000). Also, informal cross- border traders import essential and scare commodities into their countries (Mijere, 2006). It is estimated that cross- border women traders in West Africa employ one or two people and support average of 3.2 children, in addition to 3.1 dependants who are not their children or spouses (UNIFEM, 2008)

UNIFEM, (2008) reports show that women constitute between seventy to eighty percent of people that are engaged in cross - border trade. They are mostly actively involved in border trading activities such as moving goods through border crossing points as trade is one-activity women can take-up with little or no resources. However, women had been engaged in long- distance trade before this time and had been earning incomes for household support. But aftermath of $1980^{\circ e} \mathrm{~s}$ economic crisis, Informal cross border trade becomes a safety net for the unemployed in African, providing sources of income without formal education(Mijere,2006). By ignoring women "s informal trading activities, African countries are neglecting a significant proportion of their trade

Ironically, ICBT is often perceived as illegal dealing in stolen goods, banned goods, or illegal drugs. This perception has unfortunately resulted in most countries focusing only on formal international trade with complete disregard to the informal aspects of the trade despite the significant contributions that the trade makes to the overall national economy. Informal cross border trade is coming under the spotlight in connection with the need to alleviate poverty in general and feminized poverty in particular. For this to happen effectively and 
efficiently, policy and institutional reforms should create an enabling environment for crossborder women trader. Challenges to free and profitable participation in trade have to be identified and documented. This study draws attention to the circumstances of women traders across West African borders within the context of the evolving policy that must take full cognizance of the situations of women and their small-scale cross- border trade activities. The findings in this study will lay basis for efforts by individual countries to offer concessionary facilities to women traders so that they can realize their full potential, ultimately enabling them to take advantage of West African Economic Liberation Policy. This study focuses on women 's capacities, their contributions to intra-West African trade, and particularly on crossborder trade and its constraints.

\section{1. Brief Literature Review and Theoretical Framework}

Tsikata (2009) noted that since the colonial period, West African women have been involved in trade, both in their own countries and across the borders, particularly in the distribution of food and small consumer items and trade services. Their active involvement in small -scale trade is linked with the gendered construction of the colonial economy and society, which allowed male access to formal education and employment in the colonial bureaucracy and other forms of formal employment. Many women have entered the informal economy owing to lack of other opportunities for them. Women traders have used global economic openings to become cross border traders. As noted by Randriamoro(2008), women in cross border trade is not believed to be substantial, but not recorded in trade statistics because women often cross informally or transport goods using methods such as head loading, which are not included in trade statistics. Their methods are a function of scale of their trade, which is very small. Men on the other hand, are more involved in visible cross border trading, trade facilitation, and regulatory activities (Morris and Saul, 2000)

A study carried out by Marpahtia et al (2001) found out that apart from products such as spare parts, used tyres and cars, which men sell, West- African cross border trade is largely a female activity. Because of the segmentation of labour in production and distribution, men and women have traded in distinct products in the market places (Economic Commission for Africa, 2010). Traditionally, women cross border traders were engaged in the sale of unprocessed and processed food such as fish, salt, and foodstuffs. Women were confined to jobs such as food selling and shop assistance in businesses at border crossing. Now they are now involved in cross- border trade, involving a range of goods and services, which has resulted in new transnational networks, supported by commonalities in language, culture and kinship System (Economic Commission for Africa, 2010). Women cross border trading (WCBT) are now more diverse and engage in a higher value and volume of goods than the stereotypical market selling few items on every market day (Morris and Saul, 2000). WCBT is now found in agricultural produces, agricultural processed goods, and light manufacturing commodities (Dejere, 2001).

There are several benefits accrued to women in cross border trading according to scholars. For instance, cross border trade enabled many women to become financially independent (Desai, 2001). Many female household heads had broken out of poverty through cross border trading (Muzvidziwa, 1998). Many women opted for cross border trade as a strategy to ease competition and cope with poverty (Shamu, 2005). Men and women alike are involved in African Cross-border trades as producers, traders and consumers (GENTA, 2001). Despite the fact, WCBTs had made huge contributions to Africae s economy. But they were neglected by mainstream trade policies and institutions and as such undermining the 
profitability of their activities (Mzizi, 2010). The future of development of Africa lies with women and youth who should be empowered to play an expected role

Ironically, despite the benefits from cross- border trade to women, there are several challenges peculiar to women. This is because of critical differences in men and women es positions in the economies and societies in West- Africa .Many researches on WCBTs have identified a lot of challenges and constraints encountered by WCBTs. According to Kabira (2011), WCBT path is strewn with difficulties and danger as ICBT is a risky business for women (Matsuyama, 2011). WCBTs are open to economic and personal risks such a robbery and harassment (IOM Zimbabwe Newsletter, 2011). According to Matsuyama (2011), WCBT do not benefits from preferential tariffs, and face risks of abuse, harassment, exploitation and are exposed to extreme vulnerability. They are vulnerable to abuse, exploitation and health risks (Matsuyama, 2011). Mazinjika (2009) discovered that most WCBTs have little knowledge of their countries customs. Protocol and the few that knows it have little motivation to use it to facilitate trading activities.

Other problems include: inadequate public and private transportation, multiple control posts, multiple and arbitrary taxation of goods, insecurity and harassment, limited market information, communication costs, language barriers and problem of exchange (Dejene, 2001, Mzizi, 2010, Njikam and Tchouassi, 2010). A problem of exchange rate mainly between the CFA, France and Nigerian Currency- the naira is a fundamental problem due to lack of formal exchange bureaus. Because of this, most traders go to informal (black) market exchange where premium is often high and volatile.

From 2007-2009 of the 2000 WCBT surveyed by UNIFEM a great majority stated that the proceeds from trading is the main source of income for their families (South Africa, 2009). WCBTs ${ }^{\text {ee }}$ address vital issues of livelihoods such as food and income security (Mzizi, 2010). They contribute to food security, by trading in food products from areas of surplus to areas of deficit (Dejene,2001). Because women cross border trading is carried out informally, measuring their contributions to national and regional economic development is difficult (Dejene, 2001).

\section{RATIONAL CHOICE THEORY}

The basic principles of rational theory are derived from neo-classical economics. Based on a variety of different models, Freidman and Hechter (1988) put together what they describe as "skeletal" model of rational choice theory (Ritzer, 1996). The focus of rational choice theory is on actors. Actors are seen as being purposive, or as having intentionality. That is, actors have ends or goals toward which their actions are aimed. Actors are also seen as having preferences in terms of values, and utilities (Macy and Fletch, 1995). The main assumption of this theory is that any action by an individual is a purposive behaviour, which will hold benefits for the actor in some ways. Rational Choice theory sees individuals behaviour as motivated by their wants, needs and goals and that individuals acts with specific given constraints that are based on the information they have about the conditions under which they are acting. Rational individuals choose the alternative that is likely to give them the greatest satisfaction (Carling, 1992 and Coleman 1973). What distinguishes rational choice theory from these other forms of theory is that it denies the existence of any kinds of action other than the purely rational and calculative. All social action, it is argued, can be seen as rationally motivated, as instrumental action, however much it may appear to be irrational or non-rational (Scott, 2000). 
The relationship between individuals ${ }^{e e}$ wants and constraints in achieving them can be seen in the pure technical terms of relationship of a means to an end and since it is not possible to achieve all their desires and goals and they must make choices in relation to both their goals and the means of achieving them. Rational Choice Theory holds that individuals usually anticipate the outcomes of alternative courses of action and calculate that which will be best for them (Levin and Milgrom, 2004). Rational Individuals are believed to choose the alternative that is likely to grant them their goals at minimal cost. There are two types of decision-making identified by Rational Choice theorist, namely involvement decisions and event decisions. Involvement decisions are those in which choices are made to become involved in an act or behaviour, and the continuity or retreat from such behaviour depends on the weight of costs and benefit of it, while event decision are those in which the strategies of carrying out an action are determined. If these strategies are difficult, such course of action or behaviour will not be taken(Green, 2002) .

The argument of this research is anchored on the notion that economic activity of Cross-border trading is rooted in rational choice theory as any individual before opting for Cross-border trading will have to weigh the pros and cons of such decision. And since Crossborder trading does not require much capital, it is an easy option for women as a means of easing economic repression. Along the line as Cross-border trader realizes that the rewards/profits accrued from Cross-border trade far out weight it costs, they develop tactics to cope and minimize whatever costs and difficulties associated with the trade. It goes a long way in explaining why there is a steady increase in women 's involvement in ICBT in recent times by bring to fore the fact that an activity become attractive if its potential benefits outweighs the potential danger and cost associated with it. That is, it adequately explained why women persist in ICBT despite the challenges and difficulties associated with the trade.

\section{METHOD OF DATA COLLECTION}

This research work utilized only qualitative method of data collection, because of the itinerary nature of informal trade. Also there is no available data based for scholars working in informal economy. Qualitative methods of data collection were therefore found appropriate for this type of work. The method of data collection includes the following, a, Unstructured observation, b, Focus Group Discussion (FGDs), c, In-depth Interviewing (IDI) and d, key informant Interviewing (KIIs)

The essence of triangulating the method of data collection is that one method $\mathrm{s}$ strength will cover the weakness of another method. Unstructured Observations were carried out at Seme Border, Iyana-Iba and Mile- Two motor parks. These are motor parks were utilized for conveying of goods coming from Abdijan, through Ghana, Togo and Benin republic to various destinations in Nigeria. The essence of unstructured observation was to get familiar with the operations of women traders coming from various West - Africa countries.

Two (2) Focus -Group Discussions each was carried out at Iyana-Iba and Mile- Two motor parks. It was virtually impossible to conduct FGD at Seme Border because of visible fear of Uniformed Personnel expressed by women traders. Focus group discussions were carried out with women traders at Iyana-Iba and Mile Two Motor Parks while waiting for their goods to arrive or while waiting for boarded vehicle to fill up. The researcher and research assistants had to go to the parks to wait for the women to arrive. However, the consent of women to participate in FGDs was sought through the contact persons (Drivers). The focus group discussions were recorded and later transcribed and grouped into themes. 
In-depth-Interviewing (IDIs) were carried out at various times and at different places. There is no specific day that the interviews were carried. Sometimes, the researcher and research assistant had to follow the women into the cab in order to get them interviewed. The purpose of the interview was normally explained to them in order to get their consent for interview.

The key informants include the custom officials, immigration and police officers and the drivers at the motor parks where the women board vehicle to their destinations. Women involved in cross border trade were interviewed for the period spanning over eight months. The data was analyzed through content analysis and ethnographic summaries.

\section{RESULTS AND CRITICAL DISCUSSION}

\section{1. Motivation and Social networking among women traders in informal cross border trade}

In general, a person will never start a business without motivation (Robertson, 2003). Motivation is an important factor in the decision to start a business. There are various and possible motivational factors that could influence women entrepreneurial behaviours despite the fact that culturally women are expected to stay at home, take care of children, and play other social roles. Women are the first primary agent of socialization as it has been posited that absence of mothers at home over a long period often lead to deviance behaviour among children (Olutayo 2005). Despite the culturally approved roles of women in society, majority of the women were engaged in cross border trading as means of survival, for economic reasons and to supplement the family income. One important finding on motivating factor is the "quick returns on investment and location opportunity". For some women, Informal cross border trading (ICBT) was added to their jobs because of proximity of border (Seme Border) to their residences. The proximity enables them to do quick trading before returning home at the close of work. Some of the respondents illuminate on this issue.

There is no other means to support my husband, who had been retrenched from his place of work. ICBT brings in quick money and it has helped us to live above poverty level in my household (Female / 35 years/ IDI/ February, 2013)

There is no other way to generate income to train my children and support my husband. I will continue to remain a cross- border trader because it generates quick money. Since there is no other means to get money to feed, the only means I know is what I will stick to (FGD/ 40years/ April 2013)

I live not far from Seme Border. Most times, I travelled to Cotonou to purchase some goods for sale at the office .I added ICBT to my job because my salary is not sufficient to meet my financial burdens, I will continue as a cross border trader until my financial burdens decreases (IDI/ 38 years/ April 2013).

The location opportunity/advantage taken by the respondent above was collaborated by the custom personnel. A key-informant informed us that, there are usually inter marriage between Nigerians and Beninois and some of them live around the border town. The dual citizenship gives them advantage in crossing from one countryees border to another. This has 
been one of the obstacles in preventing immigration officials from enforcing the law, as people will always claim they are in their countries.

Findings in this study reveal the social networking of women informal cross border traders are involved in. Majority of Women ee traders are introduced to this informal trading by friends and other relatives. These friends and relatives taught them the rules of the game, that is, how to cope and succeed in spite of difficulties associated with the trade.

\section{2. Trading activities across ECOWAS sub region borders - known and unknown risks}

The main findings show that women in informal cross border trade engage in sales of different and diverse commodities, which are, categorize differently. The categories include agricultural products like rice, pastry, cooking oil, beef and chicken and different kind of fruits. Other category is textile materials, which include the new textile materials like Ankara, Guinea Brocade, Lace materials among others. Old second -hand materials called "okirika". Okirika includes different types of wears, shoes and bags and bed spreads. All these items are categorized as banned goods. All materials or items mentioned above are classified as banned goods in Nigeria.

In sourcing for all these materials, the findings reveal that women in informal cross border trading had to travel to various markets in Benin republics to buy all these commodities. Some went as far as to other countries like Ghana, Togo, and Cote- D Tvoire to purchase some commodities if such commodities are not available in Benin Republic. The findings reveal that women traders in informal cross- border trade across sub-ECOWAS region do not use available formal systems and structures for their transactions, which exposes them to known and unknown risks along the region. In addition to this, their mode of operations makes it difficult for regional trade policy initiatives to have any significant impact on their business. Some Key informants were apt on this:

There are policies that guide international trade that, anyone who engages in
it must comply with. The status of women had been raised from an ordinary
woman to international trader immediately she makes a decision to leave her
country and cross to another country to trade. However, most of the women
in informal trade are not knowledgeable about the law that guides
international trading. They do not know how to be a cross border trader.
Most of them are not registered to advantage the full advantages of
ECOWAS Liberalized policy (KII/59 years/March, 2013)

All kinds of women on daily basis ply Lagos Seme Border en-route to other towns in Nigeria. It is observed for several years that cross- border traders do not have legal documents needed to facilitate such trade. Most of them do not have ECOWAS passport and International identity. Majority of the women in cross- border trade are illiterate, but have business initiatives and are so desperate while engaging in the business. The literate ones among them are very few (KII/55 years/ March, 2013).

Ironically, women traders show little knowledge about policies guiding cross- border trading except the fact that they had to carry their international passport when cross- border which most of them claimed they do not possess. Few of them that possess international passport believe that they will be delayed at the transit point and would be asked to pay a fee of two thousand naira before they could enter. Most of the women show little motivation to 
register and pay little tax on their goods. They are not aware of the fact that they can go to purchase goods with minimum of $\$ 500$ if they are registered, and without going through the bush-parts, or exposing their goods to seizure. Women traders largely want to continue with the old way of trading they have been socialized into and had practiced for many decades. The preference for the old ways had been evident in the manner women traders had been operating along ECOWAS-Sub region borders. In addition to this, even those who had never been exposed to trading but had taken advantage of social networking they are involved in to get into informal cross border trade operate in the same.

Women traders gave several reasons for not been motivated or confident that registrations will assist them in cross- border trading. Women advance cultural reasons as to the fact that they are women who are taking initiatives to train, cater for their children, and assist in house hold economy. In so doing, they are helping themselves, helping families, their communities, and society in general. The general perception of women in informal cross border trade is that they are contributing significantly towards the development of nations, through provision of scare items, therefore they should not be hindered in conducting their business successfully. Women traders also look at the issue of time and believe that they need to conduct their business quickly in order to return home to take care of their children and spouses. Going through formal process of registrations will affect the time they need to conduct their businesses and return home.

A key-informant collaborate on this

When an immigration officer on guard prevent some of these women traders, from entering the border, they are always ready to beg and plead with us, appealing that they had to take care of their families. While we allow the policy regulation to override the sentiments expressed by these women, some of them find their ways through the push paths with the assistance of (Beninois). However, I believe that women traders should show themselves to immigration officer and registered because of their safety and inherent danger associated with travelling to another country (KII/ 45 years/ June, 2013).

Some of the women believed that they small scale traders that operate with small capital ranging from thirty thousand naira to hundred thousand naira. Women traders also expressed the fear of tax payment. They believe that they might not be to afford payment of taxes, since they operate at the small-scale level. Payment of taxes will eat deep into their profits. They also expressed doubt if custom personnel will ask them to pay appropriate tax. To women respondents, custom officials are not sincere, they will always find faults with the hope to extract more money from them than the exact amount they are to pay if they truly registered as traders. A woman respondent in FGD expresses her fear:

I doubt if official rate of taxation will be applied. We all knew from experience that customs, immigration, and other security men will always find reasons to demand more money in their individual capacities (FGD/ 47 years/ May 2013).

Women generally were of the opinion that any policy that appears to make it difficult for customs, immigration and security officials to receive bribe from women traders is bound to fail because the officials will not allow it to operate smoothly. 


\section{3. Challenges of Women in Informal Cross Border trade}

Several challenges have been associated with cross border trading, more so with the informality associated with women traders"e work. Obstacles do not necessarily stem from policy regulation, but from informality of women's work. Several obstacles expressed by women traders range from attitude of uniformed personnel, to language barriers, sexual harassment, fluctuating exchange rate, vulnerability to HIV/AIDs and inadequate transport facilities. One of the obstacle women trade perceived as the most serious challenge they face is the attitude of uniformed personnel. Their responses is not surprising considering the fact that uniformed personnel activities are based on formal procedure of operation, which contradicts informality of women traders "e activities. Informalities of women 's work in crossborder trading prevent necessary revenues in form of taxes that might have been accrued to government purse.

Findings reveal that women in cross border trading are perceived as smugglers (Fayawo). Smuggling of banned goods into country is seen as detrimental to national productivity and economic growth. It is posited therefore that women in informal cross border trading are perceived as "enemy of nations". This perception brings constant acrimony between uniformed personnel and women in informal cross- border trading. In one of the unstructured observation at Customs se checkpoint, the researcher witnessed a scuffle ensued between a custom officer and a woman trader which eventually resulted in custom officer physically assaulting the woman.

One of the respondents says:

Custom is the main challenge WCBT encounter and some people have had hypertension because of custom officials ${ }^{\text {ee }}$ attitudes of seizing their goods. Police, immigration officers are also part of the challenges of WCBT. Due to desperations by police and customs officers to get money, even when a vehicle is not carrying any contraband goods, they will still attempt to seize goods and demand for money before they can return the goods or detain the vehicle until he pays them (FGD/38 years/ May 2013).

\section{3. 1. Drivers' Theft, Robbery, and Fraud in the Market}

The findings show that majority of the women were particular about the cases of robbery by hooligans and sometimes by drivers in an attempt to help them load their goods. This problem expressed by women respondents has to do with the problem of insecurity at the border. Unstructured Observation at the border reveals that the border is porous. People from various ethnic backgrounds are within the border engaging in conducting one business or the other, more so, there are no officials on patrol to check their activities.

Another observation made at the Seme border shows that many of the WCBTs are not usually at peace until the crossers (People helping transporting goods from another country) or truck man brings their goods and even after that, they monitor the drivers of the buses they are boarding like a mother hen' until the vehicle is on the move. Observation reveals that hooligans/ Touts (Agbero) always charge women traders some amount on their goods known as "Land money". Scuffle usually ensues which sometimes may lead to stolen goods if the women trader refuses to pay land charges to "Agbero". The reasoning behind this was the perception that women in informal cross border trading are engaging in illegal business as they do, therefore, little choice is left to them than to obey the hooligans. It is reasoned that hooligans do not tamper with the women in formal cross border trading, money paid to 
hooligans could have been used for taxes if women in informal cross border trading as been properly registered. The problem of driveres stheft, robbery, and fraud is illuminated by the response of a woman in focus group discussion

There are many people at this border. Many of them are theft waiting to steal the goods of anyone who is not watchful. If one is not watchful, the hooligans at the garage will steal one"s goods. Again, the ,'agbero" will come and charge owo-ile (Land Charges) as if the land belongs to them. Moreover, if one refuses to pay, they will start dragging your goods with you. They even prefer to steal your goods than collecting owo-ile (Land Charges) from you. One needs to be very smart in this border (FGD/ 47 yrs/ April 2013)

In this era of HIV/AID, the finding reveals that none of the women respondents claimed to have contacted the disease. There was unanimous opinion that custom personnel usually harass women sexually. However, there was no one among the respondent who claimed to have been harassed sexually before by custom personnel. Their claim was understandable bearing in mind that within Yoruba culture or any other culture in Nigeria, women cannot come out boldly that she has been harassed sexually because of stigmatization involve. Ironically, there was sort of subtle approval and emotions expressed by women traders that sometimes, for a woman to prevent seizure of her goods, she might comply with the demands of custom men. The reason was that if she loses her goods through seizure, how would she cope and take care of her family. It is posited that apart from perception that women traders engage in smuggling of banned items into country, the fear of women losing their goods might also accounts for incidence of sexual harassment at borders. However, a key informant explains the situation on sexual harassment in another dimension

Harassment occurs at most routes of the border both legal and illegal routes. Altrusically, border officials spearheaded some sexual harassments moves, while women themselves engineer some. Women who ply these illegal routes while transacting business are at the mercy of themselves when caught by patrol officers on duty. However, $90 \%$ of harassments that occurred at the border areas were usually fashioned by these women. Since women traders traded in contraband goods, and were aware of the known risks involved in trading in banned goods, so, whenever they are caught and the goods were seized, they will choose to entice border officials on duty with their bodies as a means to liberate their goods rather than lose their goods. They are ready to give anything (KII/55 years/ May 2013)

Another challenge that is worth noting is the health challenges associated with crossborder trading. One of the health challenges expressed by women respondents that cut across everyone of them is the issue of stress. Majority of Women traders experience stress in the course of travelling to another country for several reasons, one reason is the fear of seizure of goods by custom officials. Other reason includes thefts by drivers or touts at the motor parks, and extortion by different uniformed men. A woman respondent explains this:

Though, the gain of CBT is high, but it is too stressful because of the challenges we normally experience on this route. However, if God has not opened another one, I will continue with this. The problem and stress associated with this trade tells on one"s health, it is not a trade one should do 
for a long time, if one wants to enjoy. The problem of CBT at Seme border is much, if you see my picture, you will realize that the stress of CBT is not good for the health (IDI/ 39 years/ June, 2013)

Despite the apparent challenges majority of the respondents say they will remain a cross border traders, because they have no other means of income to train their children. It is pertinent that point out that because of insistence of women in informal cross trade to continue with the trading, majority of them had devised several coping strategies negotiate these challenges that are worthy noting.

\section{4. Coping Strategies of Women Traders In informal Cross border trade in ECOWAS su- region}

Coping Strategy is important effort or plan devised by a person or a group to achieve any laudable objectives. Women in informal cross border trade have devised various coping strategies to negotiate challenges associated with informality of trading. Among the notable one is what is known as "Settling Drivers". Settling drivers is a means where the drivers conveying their goods act as intermediary between women in Informal Cross border trading and the custom officials. The findings reveal that drivers conveying goods for women traders usually charge women with loads higher amount than those without loads. For instance, before the removal of fuel subsidy, a bus fare from Seme border to Iyana -Iba cost two hundred naira for people without loads, while those with loads pay as much as two thousand naira to three thousand naira depending on the quantity of goods. The extra amounts are used to settle the uniformed personnel. Majority of the women prefer to pay the drivers such amount in other for the drivers to settle all the uniformed personnel.

A respondent says:

if you have paid the driver sufficiently, the driver will settle the officers, so once I pay; the customs are no longer my problems (IDI/35 years/ February, 2013)

The finding also reveals that in a situation where customs officers demand for more money the driver cannot afford, the WCBT contribute more money among them to settle such officers. Significantly, all WCBT employ this strategy, they differentiated between "seized" and "seizure". When one "s goods is "seized", there is still hope of recovering such goods. But when it enters "eizure", it cannot be recovered. Thus most women bribe customs officials, in other to avoid their goods from entering "seizure" and these money is accompanied with lots of pleas. It was also reveals that WCBT are sometimes charge a particular amount to bail their goods. A respondent says:

Customs have specific period for specific goods, for examples, if it is the era of rice seizure, one will be billed two thousand naira for a bag of rice and one thousand five hundred to bail a cartoon of turkey. This implies that the number of bags of rice or cartoons of turkey one can afford to bail is what one takes home; as such, it will affect the profit margin. The moment we bail out goods, such trip will yield no profit, for all the profits have been given out to custom to bail out the goods (IDI/ 32 years/ January, 2013). 
A significant proportion of WCBT employ this strategy. However, some women go to the market every day to buy in small quantities, the rationale behind this is to avoid seizure by custom officials. Apart from settling the drivers to act as intermediary between them and the custom officials, some women also divide their goods into different parts with the belief that if they carry their goods in one vehicle, custom officials are likely to seize them. Nevertheless, if the goods are divided and send in different vehicles, it is not likely that all the goods will be sized.

\section{SUMMARY AND CONCLUSIONS}

One of the Millennium Development Goals (MDGs) is empowerment of women and reduction of poverty among women. Informal trade is a vital part of the nations ecenomy that cannot be ignored. Majority of women are involved in micro and small informal businesses which contribute more than $97 \%$ of all enterprises, $60 \%$ of the nation ${ }^{\text {ee }}$ GDP and $94 \%$ of the total share of the employment in Africa (Mayoux 2001, Ukonu and Ehiabi, 2011, Fapounda, 2012). One of the informal trade activities is ICBT. ICBT has provided jobs for significantly number of people particularly women. It has provided easy entry for the unemployed, and the retrenched. It has helped many people especially women to train their children and support both their spouses and provide for household economy. It has enable people to live and rise above poverty level. The findings from this study shows that majority of women are into this trade to support family income, to train children and support their spouses

However, despite the significant advantages that informal cross border trading has provided for women in particularly, much needed to be done on the part of government and nongovernmental organization in educating women on the continuous inherent dangers associated with informalities of their trading activities. Of importance to this issue is the the known risks associated with informalities. Cross-border trade involves high levels of insecurity related to both persons and goods from corrupt law-enforcement agencies and touts. Traders carrying money run the risk of having money seized. This study collaborate the study carried out by (Ibeanu, 2007) that one in two respondents had experienced some form of harassment during their current trip. The Nigeria-Benin border is considered particularly problematic and has defied solution in spite of joint border patrols organized at the behest of their presidents. The insecurity of traders is compounded by the fact that they often do not have valid travel documents and do not always know whether they need to pay taxes on the goods they are carrying.

Many traders had devised strategies to cross borders with their goods as situation at the borders fuel extortion. Not surprisingly, extortion by law enforcement officials is the most frequently mentioned problem by those interviewed. Significantly, majority of women reported that their businesses had been adversely affected .It also reasoned that unknown risks might occur at any time when one travels outside one s country, and without the knowledge of immigration officers, Government might not be in position to take any diplomatic decision.

\section{Recommendations}

1. There is need to address the issue of informality in mainstream trade policy making and to strengthen the notion that women informal traders are also an important client of Ministries 
of trade and regional economic communities. Every effort should be made to enable women to build trust in formal cross- border trading structures rather than continuing with the old practice of conducting which may be regarded as costly illegal trade. Apart from the fact that the illegality poses unpredictable costs that make planning difficult, it prevents them from securing recognition from formal government structures as important traders which leaves their contributions unrecorded and therefore not recognized or documented.

2. More researches should be conducted to document the experiences of women traders at all border points and within their business premises. While it will be important to find ways of quantifying their participation, it would be better from a strategic viewpoint to use qualitative methods to assess their experiences and learn from them about their experiences, knowledge and constraints involve in regional trade

3. The use of Mass Media for dissemination of information concerning trade-policy on subECOWAS region should be encouraged. National government, regional bodies, and most civil society organizations should educate or empower these women with knowledge on how they can participate meaningfully in regional trade WCBT. Often these women rely on each other for socio- economic support and information.

4. Policy implementation should include Production and dissemination of innovative knowledge products to: (i) ensure visibility of the contributions of women cross border traders to wealth creation, poverty reduction, employment creation and regional integration; (ii) disseminate best practices in supporting women informal cross border traders; (iii) fight stigmatization and violence against women informal cross border traders.

\section{Biography of Mrs Olabisi, S. Yusuff}

Olabisi, S. Yusuff is a lecturer at the Department of Sociology, Lagos State University, Nigeria. She is also a doctoral student at the Department of Sociology, University of Ibadan, Oyo State-Nigeria. Her research interests include Sociology of Development, Gender/Women Studies and Family Studies. She has published in local and international journals. She is happily married with children

\section{References}

[1] Ackello-Ogutu, C. (1997). "Unrecorded cross-border trade between Kenya and Uganda: Implications for food security." SD publication series, Office of Sustainable Development Bureau for Africa, USAID, Technical Paper 59, July.

[2] Cagatay N., Ozler S., World Development 23(11) (1995) 1883-1894.

[3] Carling T. (1992). Social Division. London. Verso.

[4] Chichilinsky G. (2002). Globalization and Cross Border Exchange. Available at: www. Amalik.iijournals.com. Accessed March, 2012.

[5] Coleman J. S. (1995). The Mathematics of Collective Actions.

[6] Dejene V. (2001). Women"s Cross - Border Trade in West - Africa. Available at: www. Widetech.Org . Accessed February, 2012. 
[7] Desai M. (2009). Women Cross Border Traders Rethinking global trade. Available at: www. Pelgrave.journals.com, Accessed February, 2012.

[8] Economic Commission for Africa, (2010). Gender and Intra Africa trade: The Case of west- Africa. Available at www. UNESCA .Org. Accessed March, 2012

[9] ECOWAS-WAEMU, (2006). "Regional integration for growth and poverty reduction in West Africa: Strategies and plan of action." regional strategy paper prepared by the WAEMU Commission and the ECOWAS Executive Secretariat, Abuja and Ouagadougou, December.

[10] Fapounda T. M., British Journal of Arts and Social Sciences 4(1) (2012) 35-46.

[11] Goldberg, P. K. Pavenik, N.L., J. Dev. Econ. 72 (2003) 463-496.

[12] Green S. L. (2002). Rational Choice Theory: An Overview .A paper prepared for the Baylor University Faculty Development Seminar on Rational Choice Theory. Available At: www.business.baylor.edu/steve/green1.doc.Retrieved May, 12014

[13] Ibeanu O. (2007). "Beyond declarations: Law enforcement officials and ECOWAS protocols free movement of persons and goods in West Africa." CLEEN Foundation. Available at: www.Cleen.Org.Accessed March 2012

[14] IOM Southern Africa Newsletter, (2010). Informal Cross Border Trade. Eye Issue on migration Health. Available at: www. Iomzimbabwe. Org. Accessed March 2012

[15] Kabira W. M. (2006). Women and cross Border Trade in East Africa . Available at: www.library .fes.de. Accessed March, 2012

[16] Levin J., Milgrom P. (2004). Introduction to Rational Choice Theory. Available at: www. Standford.edu/Jdlevin/econ\%2002/choice\% 20Theory Pdf.

Retrieved May 3, 2014

[17] Macy M., Flach A., Annual Review of Sociology 21 (1995) 73-92.

[18] Mayoux S. (2001). "Jobs, Gender and Small Enterprises: Getting the Policy Environment Right", ILO Working Paper on Series on Women 's Entrepreneurship Development and Gender in Enterprises- WEDGE, NO. 15

[19] Matsuyama R. (2011). Risky Business of informal cross border trade. Available at: www. Afronews.com. Accessed April, 2012.

[20] Mijere N. J. (2006). Informal Cross border Trade in the South African development. Available at: www. Ossrea .com. Accessed April, 2012

[21] Morris G., Saul M. (2000). Women“s Business links; A preliminary Assessment of Women Cross border Traders. Available at: www. Pdf.usaid .gov.

Accessed April, 2012.

[22] Muzvidiziwa V. (1998). Cross Border Trade: A strategy for climbing out of Poverty. Available at: www. Digital .lib.msu.edu. Accessed April, 2012.

[23] Njikam O., Tchouassi G., Academic Journals 6(5) (2011) 22-31.

[24] Olutayo O., Ibadan Journal of the Social Sciences 3(2) (2005) 67.

[25] Ritzer G. (2000). Sociological Theory. Fourth Edition. McGRAW Hill International Editions. Sociology Series. 
[26] Robinson S., Journal of Developmental Entrepreneurship 6(2) (2003) 151-167.

[27] Scott J. (2000). Rational Choice Theory. Halcli A. and Webster F. (eds) from understanding Contemporary Society: Theories of the Present. Sage Publications.

[28] Shamu S. (2005). Gender and Entrepreneurship: Survival strategies of Tanzania-bound Zimbabwean Informal Women Cross Border Traders. Available at: http://www.ossrea.net. Retrieved April, 2012.

[29] Tsikata D. (2009). "Informalization, the informal economy and urban women's livelihoods in sub-Saharan Africa since the 1990s." in S. Razavi (ed.), The Gendered Impacts of Liberation: Towards "Embedded Liberalism"? Routledge, New York.

[30] Ukonu O. F., Ehiabi T. A., An International Multi-Disciplinary Journal 5(3) (2011) 20.

[31] UNIFEM, 2008. Unleashing the Potential of Women in Informal Cross Border Traders to Transform Intra-African Trade. Available at: www.UNIFEM.org. Accessed May, 2012.

[32] M. N. Modebelu, F. K. Igwebuike, International Letters of Social and Humanistic Sciences 4 (2014) 40-48.

[33] Audu Andrew Jatau, International Letters of Social and Humanistic Sciences 8(1) (2014) 18-27.

[34] Benedicta Ehi Momodu, International Letters of Social and Humanistic Sciences 13 (2014) 64-70.

[35] Adebowale Adeyemi-Suenu, International Letters of Social and Humanistic Sciences 13 (2014) 89-94.

[36] Adebowale Adeyemi-Suenu, International Letters of Social and Humanistic Sciences 14 (2014) 1-6.

[37] Ramesh Pandita, International Letters of Social and Humanistic Sciences 17(2) (2014) 128-149. 